\title{
Journal of Information Systems and Informatics
}

Vol. 3, No. 1, March 2021 e-ISSN: 2656-4882 p-ISSN: 2656-5935

http://journal-isi.org/index.php/isi

Published By DRPM-UBD

\section{Penerapan Aplikasi Location Based Service Dalam Penangganan Gangguan Jaringan Berbasis Mobile}

\author{
Dwi Ade Hanyani Capah ${ }^{1}$, Tazkiyah Herdi ${ }^{2}$
}

Fakultas Ilmu Komputer, Universitas Mercu Buana, Jakarta, Indonesia
Email: ${ }^{1}$ dwi.ade@mercubuana.ac.id, ${ }^{2}$ tazkiyah.herdi@mercubuana.ac.id

\begin{abstract}
Abstrak
Location Based Service adalah kemampuan untuk mencari lokasi geografis dari mobile device dan menyediakan layanan berdasarkan lokasi yang diperolehnya. Perkembangan aplikasi location base service sudah banyak digunakan saat ini, salah satu bidang yang perlu diterapkan aplikasi tersebut adalah penanganan gangguan jaringan pada perusahaan jasa. Pada bidang penanganan gangguan jaringan terdapat masalah yaitu dimana masih ada keterlambatan dalam penanganan gangguan, hal tersebut dikarenakan lamanya pencarian lokasi gangguan. Tulisan ini bertujuan untuk meningkatkan penanganan gangguan jaringan dengan menggunakan mobile device. Dengan mobile device yang terintegrasi dengan location base service dapat mampu menyelesaikan masalah keterlambatan penanganan gangguan jaringan.
\end{abstract}

Kata Kunci: Gangguan Jaringan, Location Based Service, Mobile Data

\section{PENDAHULUAN}

Location Based Service atau disingkat LBS adalah kecakapan untuk mencari daerah geografis dari perangkat telepon genggam dan menyediakan fasilitas berdasarkan lokasi yang diperolehnya [1]. LBS menghasilkan layanan informasi yang dapat dicocokkan dengan lokasi keberadaan calon penerima informasi [2][3]. Hal ini menyebabkan peningkatan nilai informasi dikarenakan penerima dapat mengasosiasikan pengetahuan atau informasi yang didapat dengan keberadaanya [4][5].

Pada saat ini penggunaan mobile device sangatlah berkembang pesat, hampir segala bidang usaha sudah menggunakannya [6][7]. Kemajuan tersebut mempermudah seseorang untuk mendapatkan informasi tempat suatu lokasi [8]. Masyarakat bisa mendapatkan informasi yang dibutuhkan dimana saja dan setiap waktu bahkan perangkat telepon atau mobile device yang masyarakat miliki dapat memberikan informasi lokasi keberadaan masyarakat secara langsung atau pun secara tidak langsung [9].

This work is licensed under a Creative Commons Attribution 4.0 International License. 
Teknologi yang terdapat pada mobile device sangat membantu seseorang dalam mengetahui titik lokasi keberadaan orang tersebut serta mengetahui juga informasi lokasi tempat yang ingin di datanginya adalah Location Based Service. Fasilitas informasi tersebut bisa diakses melalui telepon genggam atau mobile device dengan memakai jaringan dan memanfaatkan teknologi GPS, sistem LBS ini bisa dipakai dalam mengetahui posisi akurat berdasarkan titik geografis dari lokasi pengguna dan lokasi yang dituju [10]. Android merupakan salah satu platform smartphone terbaru yang dapat digunakan untuk mengimplementasikan sistem LBS.

LBS yaitu layanan berbasis lokasi merupakan sebuah teknologi layanan informasi yang bisa diakses dengan perangkat bergerak menggunakan jaringan dan bisa menampilkan posisi secara geografis titik lokasi perangkat bergerak tersebut [11][12]. LBS juga memiliki fungsi sebagai fasilitas untuk mengidentifikasi titik lokasi dari seseorang atau suatu objek tertentu, salah satu contoh menemukan lokasi tempat ibadah terdekat atau lokasi lainnya.

Pada sebuah perusahaan jasa memiliki masalah dalam penanganan jaringan yaitu keterbatanyannya dalam mennetukan lokasi, dari latar belakang tersebut maka penelitian ini dibuat untuk merumuskan sebuah aplikasi untuk mengetahui informasi lokasi data pelanggan yang mengalami gangguan dan rute jalan pada peta yang dapat diakses melalui perangkat mobile. Dengan teknologi LBS ini dapat menyelesaikan kegiatan penanganan gangguan jaringan yang menerapkan sebuah aplikasi mobile divice yang terintegrasi LBS untuk membantu para teknisi untuk mengetahui lokasi gangguan, petunjuk jalan menuju lokasi gangguan dan data pelanggan.

Dari penelitian ini bertujuan membantu para teknisi mengetahui rute tercepat ke lokasi gangguan berdasar koordinat lokasi serta memberikan informasi data teknis pelanggan yang berefek dapat mempercepat menanggani gangguan, karena letak lokasi HandHole berdasarkan koordinat lokasi cukup tepat. Sedangkan penelitian ini bermanfaat untuk mempersingkat waktu para teknisi dalam menangani gangguan, meningkatkan keakuratan dalam menetukan setiap kabel fiber optic dalam mengetahui arah handhole yang bermasalah, sehingga mempercepat waktu dan biaya yang terbuang serta berujung kepada meningkatkan kepuasan pelanggan terhadap cepatnya pekerjaan suatu masalah.

\section{METODE PENELITIAN}

\subsection{Teknik Pengumpulan Data}

Untuk menjawab dan mengungkap tujuan penelitian, digunakan metode dalam pengumpulan data. Pengumpulan data pada penelitian ini dilakukan dengan beberapa teknik, yaitu: 


\section{Field research}

Studi lapangan dilakukan untuk mendapatkan data yang sesuai pada objek yang diteliti melalui data yang bersumber dari tempat penelitian yang bersangkutan secara langsung, telah dilakukan wawancara dengan beberapa teknisi. Data yang telah dikumpulkan tersebut kemudian diolah kembali dengan mempertimbangkan aspek kesesuaian analisis.

2. Desk research

Dilakukan dengan cara mempelajari, meneliti, dan menelaah berbagai literatur (jurnal, buku, dan artikel) yang relevan dengan topik penelitian. Data yang diperoleh berupa data sekunder yang dipakai untuk memberikan landasan teori yang kuat untuk analisis yang dilakukan.

\subsection{Diagram Alir Penelitian}

Berikut ini adalah diagram alir yang digunakan sebagai bahan acuan dalam pelaksanaan penelitian:

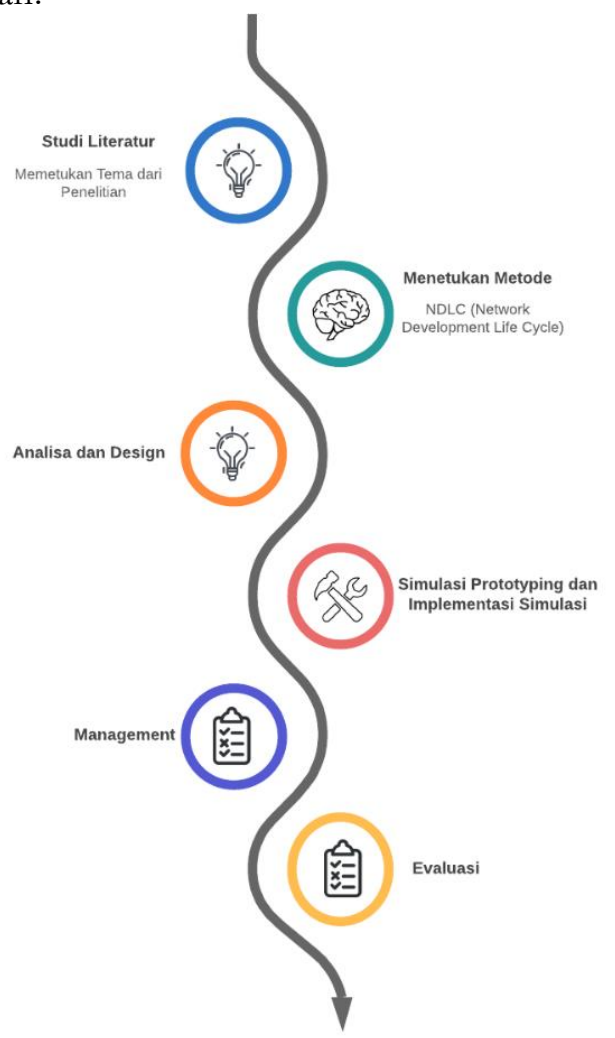

Gambar 1. Diagram Alir Penelitian 
Pada tahapan pertama yaitu menentukan tema penelitian yang akan dilakukan, dengan melakukan studi literatur berupa buku, jurnal, dan informasi yang terkait dengan tema penelitian ini. Setelah itu tahapan kedua melakukan penentuan metode yang cocok digunakan, pada penelitian ini. Pada kesempatan ini peneliti memilih menggunakan metode NDLC (Network Development Life Cycle) dikarenakan aplikasi penanganan gangguan jaringan ini sudah ada tetapi belum maksimal. Yang akan dilakukan pada penelitian ini adalah menambahkan system LBS pada penanganan gangguan jaringan.

Pada metode ini yang dilakukan pertama kali adalah analisa masalah yang muncul dengan wawancara, melihat manual blueprint dokumentasi serta menelaah datadata penanganan gangguan jaringan sebelumnya. Kemudian melakukan design yaitu dengan menggambarkan topologi jaringan yang akan terkoneksi dengan aplikasi yang akan dibangun. Selanjutnya melakukan simulasi prototyping yg dibuat dalam bentuk visio pada alur kegiatan penanganan gangguan jaringa. Pada tahap berikutnya melakukan implementasi berupa aplikasi beta untuk melihat sejauh mana aplikasi ini bekerja dan mencatat hambatan-hambatan yang terjadi. Selanjutnya managemet yaitu pembuat kebijakan dalam mengatur agar aplikasi penangannan gangguan jaringan menggunakan LBS ini dapat berjalan dengan baik. Tahapan terakhir adalah penarikan kesimpulan dari tahapan-tahapan penelitian yang telah berhasil dilaksanakan.

\section{HASIL DAN PEMBAHASAN}

\subsection{Analisa Masalah}

Analisa permasalahan yang muncul pada sistem berjalan adalah penanganan ganguan jaringan yang ada saat ini masih manual untuk bagian teknisi. Customer service mendapatkan keluahan dari pelanggan, CS mencatat nomor pelanggan. CS melaporkan kepada Admin melalui email. Heldesk melihat nomor pelanggan, kemudian menelpon PIC pelanggan untuk melakukan maintenance melalui telpon. Bila masalah tidak terselesaikan Admin akan membuat tiket gangguan untuk teknisi melalui Dispetcher. Dispetcher mengirimkan ticket gangguan melaui email, telepon, atau whatapps group. Para teknisi setelah mendapatkan tugas mereka akan membuka aplikasi google earth yang sudah di save lokasi data pelanggan atau handhole. Setelah mengetahui patokan lokasi mereka akan menggunakan google maps untuk sampai pada lokasi. Pada lokasi teknisi mulai mengerjakan gangguan tanpa ada update pada Dispetcher masalah yang di hadapi. Status perkerjaan selesai hanya terlihat pada sistem Dispetcher. Dapat dilihat dari gambar dibawah ini. 


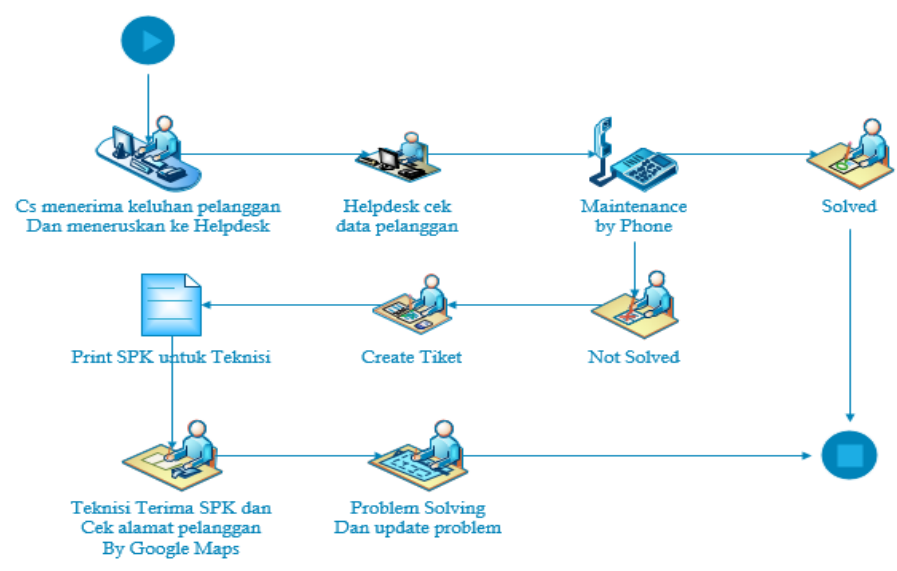

Gambar 2. Sistem Berjalan

\section{A. Solusi Penyelesaian Masalah}

Dari data-data yang telah didapatkan pada tahap analisa, kemudian tahap selanjutnya adalah tahap design. Yaitu dengan membuat gambar desain topologi jaringan interkoneksi dengan local base service yang akan dibangun. Dengan gambar desain struktur topologi dibawan ini memberikan gambaran keseluruhan dari kebutuhan yang ada. Berikut gambar topologi system yang akan dibangun.

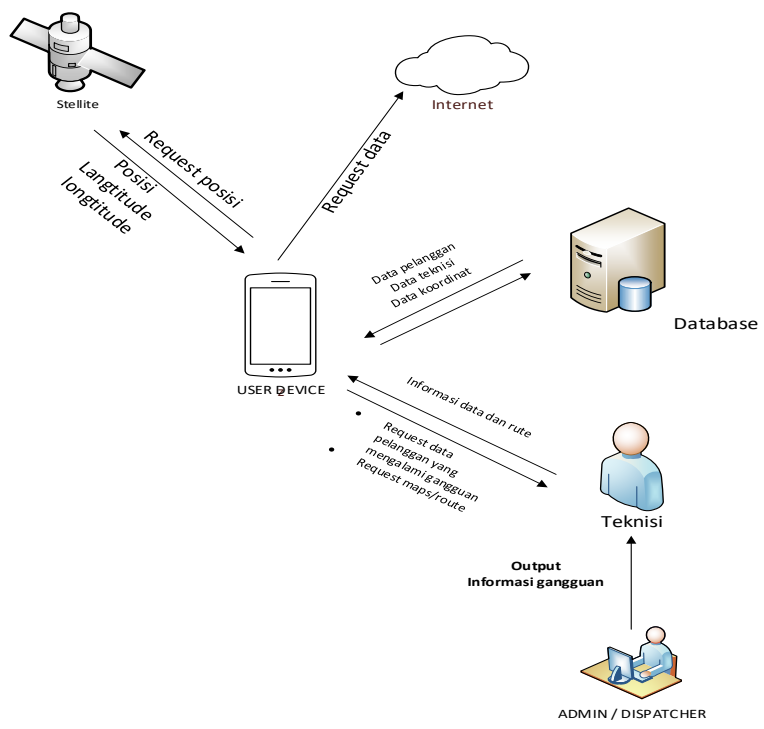

Gambar 3. Arsitektur Topologi Sistem jaringan LBS 


\section{B. Simulasi Prototyping}

Beberapa pekerja jaringan dilakukan dalam bentuk simulasi dengan menggunakan bantuan tools tertentu di bidang jaringan yaitu Packet Tracer. Hal ini dilakukan untuk melihat apakah kinerja awal dari topologi jaringan yang akan diimplementasikan dapat berjalan dengan benar atau tidak. Selain itu juga sebagai bahan melakukan paparan dan berbagi informasi dengan bagian lainnya.

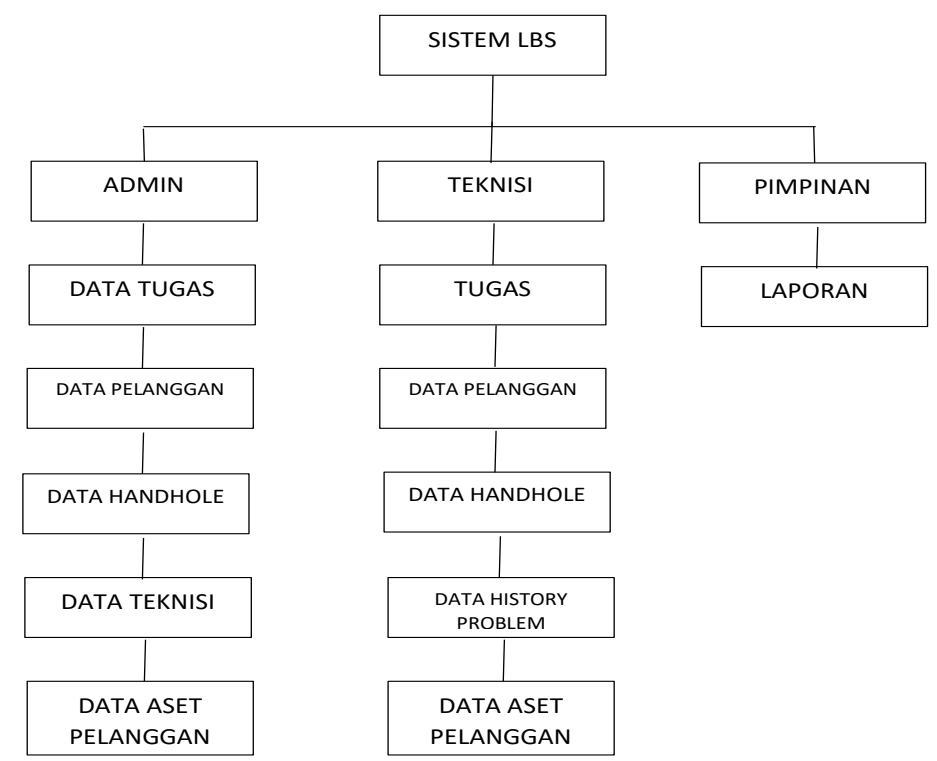

Gambar 4. Struktur Tampilan Aplikasi

Pada gambar diatas dapat terlihat system ini digunakan oleh 3 (tiga) actor dimana masing-masing actor memiliki tampilan yang dapat dilihat. Bagian admin bertugas memasukkan data tugas, data pelanggan, data hanhole, data teknisi dan data asset pelanggan. Untuk teknisi dapat melihuat tugas, data pelanggan, data handhole, data history problem dan data asset pelanggan. Sedangkan pada pimpinan dapat melihat laporan dari seluruh kegiatan yang berlangsung pada system ini.

\section{Implementasi}

Pada bagian implementasi dan pengujian sistem, telah dilakukan sebelumnya adalah bagian analisis dan perancangan sistem. Pada bagian implementasi ini akan dijelaskan asil implementasi dari aplikasi sistem yang menggunakan beberapa fungsi yang telah dibuat, terdiri dari tampilan detail tugas teknis beserta map lokasi, tampilan list data tugas dan informasi data customer. 


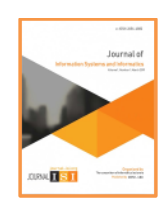

\section{Journal of Information Systems and Informatics}

Vol. 3, No. 1, March 2021 e-ISSN: 2656-4882 p-ISSN: 2656-5935
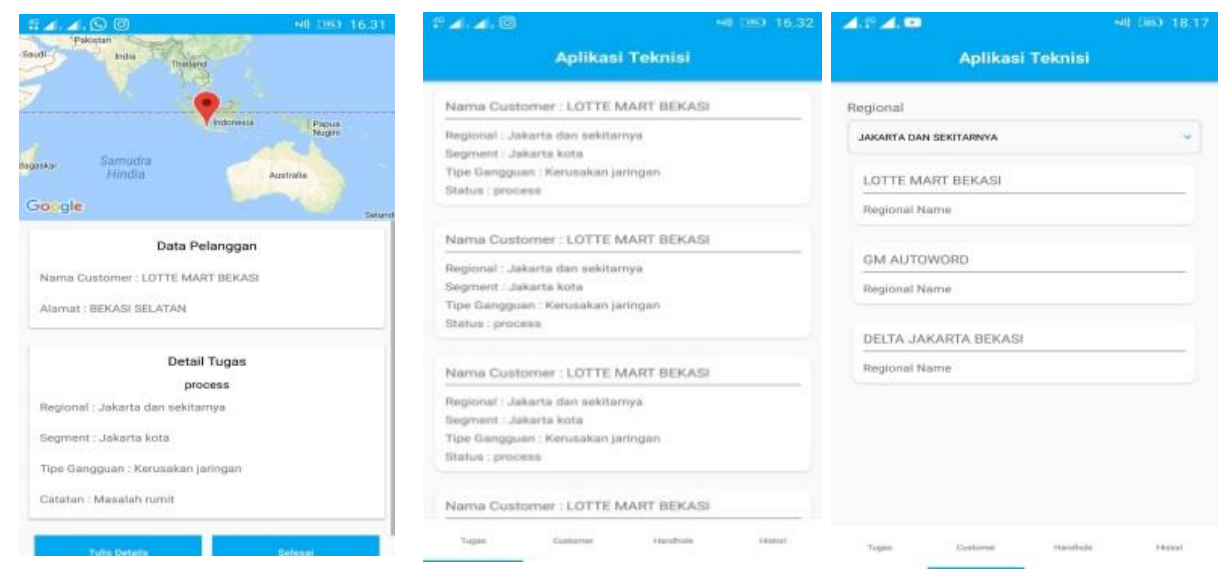

Gambar 5. Tampilan Aplikasi

Terdapat beberapa level pengguna aplikasi, disini akan di jelaskan untuk level pengguna yang harus dilakukan pengaturan, salah satu yang menjadi perhatian khusus adalah masalah kebijakan. Kebijakan dalam mengatur agar sistem yang telah telah dibangun dan berjalan dengan baik dapat berlangsung lama dan unsur reliability terjaga. Kebijakan ini sangat tergantung dengan kebijakan level pengguna dan strategi bisnis perusahaan tersebut. IT sebisa mungkin harus dapat mendukung atau alignment dengan strategi bisnis perusahaan.

\section{Evaluasi}

Hasil yang didapat dari pembahasan permasalahan yang ada adalah terciptanya sebuah program aplikasi penanganan gangguan jaringan dengan menggunakan Location Based Service. Dimana aplikasi ini tercipta dengan baik dikarenakan penganalisaan sistem, perancangan program berdasarkan data yang didapat dari metode yang digunakan, pengumpulan data yang tepat sehingga apa yang dibutuhkan sistem dapat terpenuhi. Dalam pembuatan aplikasi penanganan gangguan jaringan dengan menggunakan Location Based Service, menggunakan bahasa pemrograman PHP, JAVA dan menggunakan MySQL untuk database. Tampilan yang ada pada aplikasi dibangun cukup mudah untuk dipahami karena pemakai cukup mengklik tombol-tombol yang sudah tersedia sesuai kebutuhan dan pekerjaan. Alasan di atas dapat menjadi tujuan untuk meningkatkan efektivitas pencarian dan bisa lebih memaksimalkan karyawan atau teknisi yang terkait dengan aplikasi penanganan gangguan jaringan dengan menggunakan Location Based Service. 


\section{Kesimpulan}

Dari hasil penelitian yang telah di uraikan, maka diambil kesimpulan bahwa telah berhasil dibangun sebuah aplikasi penanganan gangguan jaringan dengan menggunakan Location Based Service yang membantu mempermudah para teknisi untuk menangani suatu masalah gangguan jaringan dengan mengetahui lokasi pelanggan, handhole, data tugas, serta history gangguan yang tersimpan otomatis setelah menganti status tugas menjadi selesai. Berhasil diimplementasikan sebuah aplikasi sistem informasi berbasis android yang mampu menyajikan data akurat dengan dukungan web sebagai aplikasi pengolahan data yang dilakukan oleh admin. Setelah melakukan implementasi maka penulis memberikan saran yang dapat dijadikan bahan untuk mengembangkan system agar lebih baik, diantarannya Diperlukan informasi lebih seperti data core management dan data handhole lebih mendetail, diperlukannya back up data secara teratur untuk mencegah hal-hal yang tidak diinginkan, pengembangan sistem dari sisi tampilan agar lebih mudah digunakan, menyadari bahwa aplikasi yang dibangun masih jauh dari sempurna, maka sebaiknya dilakukan perbaikan dengan penambahan fitur ataupun hal lain yang bisa meningkatkan performa aplikasi, seperti menambahkan fitur Augmented realty pada pencarian customer dan handhole.

\section{Daftar Pustaka}

[1] I. Nurhaida, D. Ramayanti, and R. Riesaputra, "Digital Signature \& Encryption Implementation For Increasing Authentication, Integrity, Security And Data Non-Repudiation," Int. Res. J. Comput. Sci., vol. 4, no. 11, pp. 4-14, 2017, doi: 10.26562/IRJCS.2017.NVCS10080.

[2] A. Geniusa and F. Samopa, "Pembuatan Sistem Informasi Perjalanan Dinas Kantor Wilayah Direktorat Jenderal Perbendaharaan (SIPDKanwil DJPBN)," J. Tek. POMITS, vol. 2, no. 2, pp. 366-370, 2013.

[3] B. Anwar, H. Jaya, and P. I. Kusuma, "Implementasi Location Based Service Berbasis Android untuk Mengetahui Posisi User," J. Saintikom, vol. 13, no. 2, pp. 121-133, 2014.

[4] A. Mudzakir and R. Arifudin, "Aplikasi Location Based Service Fasilitas Umum Berbasis Android," Unnes J. Math., vol. 4, no. 2, 2015, doi: 10.15294/ujm.v4i2.10464.

[5] B. Priambodo, N. Ani, and Y. Jumaryadi, "An Efficient and Affordable Push Strategy of Mobile Advertising for Micro Enterprises," Internetworking Indones. J., vol. 10, no. 2, pp. 43-48, 2018.

[6] B. Destian Wijaya, F. E.M.A, and A. Fiade, "Implementasi JSON Parsing Pada Aplikasi Mobile E-commerce Studi Kasus: CV V3 Tekno Indonesia," J. Pseudocode, vol. 2, no. 1, pp. 1-9, 2015, doi: 
10.33369/pseudocode.2.1.1-9.

[7] R. Akbar, A. Hasan, and N. Ardiesa, "Perancangan Aplikasi Web Dengan Fitur Mobile Pada Dan Perlengkapan (Studi Kasus: UPTD Balai Metrologi Dinas Perindustrian dan Perdagangan Provinsi Sumatera Barat),"J. Teknoif, vol. 3, no. 1, pp. 1-11, 2015.

[8] D. Firdaus, B. Priambodo, and Y. Jumaryadi, "Implementation of Push Notification for Business Incubator," Int. J. Online Biomed. Eng., vol. 15, no. 14 , pp. 42-53, 2019.

[9] A. Triansah, D. Cahyadi, and I. F. Astuti, "Membangun Aplikasi Web Dan Mobile Android Untuk Media Pencarian Kost Menggunakan Phonegap Dan Google Maps API," Inform. Mulawarman J. Ilm. Ilmu Komput., vol. 10, no. 1, p. 58, 2016, doi: 10.30872/jim.v10i1.21.

[10] N. Agustina, S. Risnanto, and I. Supriadi, "Pengembangan Aplikasi Location Based Service Untuk Informasi Dan Pencarian Lokasi Pariwisata Di Kota Cimahi Berbasis Android," J. Ilm. Teknol. Infomasi Terap., vol. 3, no. 1, 2016, doi: 10.33197/jitter.vol3.iss1.2016.121.

[11] G. W. Sasmito and F. Hadiansah, "Implementasi Location Based Service Rute Objek Wisata Tegal," J. INFOTEL - Inform. Telekomun. Elektron., vol. 7, no. 2, p. 107, 2015, doi: 10.20895/infotel.v7i2.37.

[12] N. Ani, M. R. Novaldi, M. Ega, and T. Mafaza, "Pemanfaatan Aplikasi Mobile Berbasis Ios Dalam Menunjang Usaha Wedding Organizer," IITK (Jurnal Ilmu Pengetah. dan Teknol. Komputer), vol. 5, no. 2, pp. 251-258, 2020, doi: $10.33480 /$ jitk.v5i2.1154. 